\title{
MDR-TB: An emerging burden for Bangladesh
}

\author{
Rajat Das Gupta
}

MPH Candidate, James P Grant School of Public Health, BRAC University, Dhaka Bangladesh.

When a TB bacillus is resistant to isoniazid and rifampicin, then it causes Multi Drug ResistantTuberculosis (MDR-TB). ${ }^{1}$ The resistance may be or may not be to other first-line drugs. ${ }^{2}$ This is a serious and emerging public health problem to the world. In 2015, there were an estimated 480,000 new cases of MDR-TB and an additional 100,000 people with rifampicin-resistant TB (RR-TB) who were also newly eligible for MDR-TB treatment. ${ }^{1}$ The World Health Organization (WHO) estimated that $3.9 \%$ of new and $21 \%$ of previously treated TB cases had rifampicin- or multidrug-resistant tuberculosis (MDR/RR-TB) in 2015. ${ }^{1}$ It was also reported that 210,000 deaths occurred due to MDR-TB globally in 2013. ${ }^{3}$ MDR/RR-TB caused 250,000 deaths in 2015 and most cases and deaths occurred in Asia. ${ }^{1}$ About 9.5\% of MDR-TB cases have additional drug resistance, extensively drug-resistant TB (XDR-TB). To date, 117 countries worldwide have reported at least one XDR-TB case. In Bangladesh, estimates showed that the prevalence of MDR-TB among new and previously treated patients was $1.4 \%$ and $29 \%$, respectively. ${ }^{2}$ Bangladesh is one of those 27 countries which have high burden of MDR-TB. ${ }^{4}$

The treatment expense of MDR-TB is very high, almost 6000 USD per person. ${ }^{5}$ In 2014, van den Hof et al. ${ }^{6}$ reported that MDR-TB patients face burdens like increase in hospital stay, loss of income and unemployment. The prevalence of MDR-TB is increasing. ${ }^{3}$ This means that the economic burden on the society and the country will be increased too in the future with increasing number of MDR-TB cases. The problem can be exacerbated by the epidemiological transition $^{7}$ which Bangladesh is facing now like other developing countries. ${ }^{8}$

Studies have found that type 2 diabetes mellitus (T2DM) is a risk factor of development of MDR-TB. ${ }^{9-11}$ Statistics also shows that Bangladesh has a huge burden of $\mathrm{T}_{2} \mathrm{DM}^{12}$ and the prevalence is increasing day by day. ${ }^{13}$ This dual burden of disease may increase the prevalence of MDR-TB among Bangladeshi population suffering from T2DM in the days coming forward.

Some may argue that the rate of MDR-TB in Bangladesh is low, thus it may not be regarded as public health problem. But it should be kept in mind that although the rate of MDR-TB is low, the total number of cases is much larger. ${ }^{11}$ In 2014 , the total estimated numbers of MDR-TB patients were 4,797. ${ }^{14}$ There is also problem with low case detection rate. ${ }^{3}$ The undetected cases remain untreated. These untreated cases can spread the disease in the community, ${ }^{15}$ resulting in more increase of the prevalence. So although the rate is low, the real burden is much bigger.
Another important concern is the economic point of view. Tuberculosis treatment is funded entirely by the National Tuberculosis Control Programme. As the cost of treatment is more, as the burden increases, ${ }^{5}$ and the total cost of treatment will rise. This will create a huge burden of the health system of the country. And as tuberculosis, specially MDR-TB is a chronic disease, the financial risk (income loss, indirect cost) for patients and their family is more. ${ }^{15} 6$ So it is a public health problem that needs to be addressed immediately.

The National Tuberculosis Control Programme should focus more on this issue for better prevention and control of MDR-TB for the betterment of the individual and the country.

\section{References}

1. World Health Organization. Multidrug-resistant tuberculosis (MDR-TB) 2016 Update. Geneva: WHO, 2016.

2. National Tuberculosis Control Programme. National guidelines and operational manual for Tuberculosis control. $5^{\text {th }}$ edition. Dhaka: National Tuberculosis Control Programme, Directorate General of Health Services, 2015.

3. World Health Organization. Global tuberculosis report 2014. Geneva: WHO, 2014.

4. Rifat M, Hall J, Oldmeadow C, Husain A, Hinderaker SG, Milton AH. Factors related to previous tuberculosis treatment of patients with multidrug-resistant tuberculosis in Bangladesh. BMJ Open 2015;5(9): e008273.

5. Afrin N. MDR-TB: Experts warn of a costly battle ahead. http://bdnews24.com health/2015/03/23/mdr-tb-experts-warn-of-acostly-battle-ahead (accessed June 2016)

6. van den Hof S, Collins D, Hafidz F, Beyene D, Tursynbayeva A, Tiemersma E. The socioeconomic impact of multidrug resistant tuberculosis on patients: results from Ethiopia, Indonesia and Kazakhstan. BMC Infect Dis 2016;16:470.

7. Mascie-Taylor N. Is Bangladesh going through an epidemiological and nutritional transition? Coll Antropol 2012;36(4):1155-9.

8. Amuna P, Zotor FB. Epidemiological and nutrition transition in developing countries:

Correspondence: Dr. Rajat Das Gupta, MPH Candidate, James P Grant School of Public Health, BRAC University, Dhaka Bangladesh. E-mail: rajat89.dasgupta@gmail.com. 
impact on human health and development. Proc Nutr Soc. 2008 Feb 1;67(01):82-90.

9. Baghaei P, Tabarsi P, Moniri A, Marjani M, Velayati AA. Impact of diabetes mellitus on tuberculosis drug resistance in new cases of tuberculosis. J Glob Antimicrob Resist 2016 Mar 31;4:1-4.

10. Fisher-Hoch SP, Whitney E, Mccormick JB, Crespo G, Smith B, Rahbar MH, et al. Type 2 diabetes and multidrug-resistant tuberculosis. Scand J Infect Dis 2008;40(11-12):888-93.

11. Rifat $\mathrm{M}$, Milton AH, Hall J, Oldmeadow C, Islam MA, Husain $\mathrm{A}$, et al. Development of multidrug resistant tuberculosis in Bangladesh: a case-control study on risk factors. PloS ONE 2014;9(8):e105214.

12. International Diabetes Federation. IDF Diabetes Atlas. $7^{\text {th }}$ Edition. Brussels: IDF, 2015.
13. Bhowmik B, Afsana F, My Diep L, Binte Munir $\mathrm{S}$, Wright E, Mahmood S, et al. Increasing prevalence of type 2 diabetes in a rural Bangladeshi population: a population based study for 10 years. Diabetes Metab J 2013;37 (1):46-53.

14. National Tuberculosis Control Programme Tuberculosis control in Bangladesh, Annual Report 2015. Dhaka: National Tuberculosis Control Programme, Directorate General of Health Services, 2015.

15. Shah NS, Wright A, Bai GH, Barrera L, Boulahbal F, Drobniewski F, et al. Worldwide emergence of extensively drug-resistant tuberculosis. Emerg Infect Dis 2007;13(3):380-7.

16. Tanimura T, Jaramillo E, Weil D, Raviglione M, Lönnroth K. Financial burden for tuberculosis patients in low-and middle-income countries: a systematic review. Eur Respir J 2014;43(6):1763 $-75$. 